University of Massachusetts Amherst

ScholarWorks@UMass Amherst

1993

\title{
Determination of Total Mercury in Waters and Urine by Flow Injection Atomic Absorption Spectrometry Procedures involving On- and Off- line Oxidation of Organomercury Species
}

Julian Tyson

University of Massachusetts Amherst

C P. Hanna

University of Massachusetts Amherst

S McIntosh

Follow this and additional works at: https://scholarworks.umass.edu/chem_faculty_pubs

Part of the Chemistry Commons

\section{Recommended Citation}

Tyson, Julian; Hanna, C P.; and McIntosh, S, "Determination of Total Mercury in Waters and Urine by Flow Injection Atomic Absorption Spectrometry Procedures involving On- and Off-line Oxidation of Organomercury Species" (1993). Analytical Chemistry. 1308.

Retrieved from https://scholarworks.umass.edu/chem_faculty_pubs/1308 


\title{
Determination of Total Mercury in Waters and Urine by Flow Injection Atomic Absorption Spectrometry Procedures Involving On- and Off-Line Oxidation of Organomercury Species
}

\author{
Christopher P. Hanna and Julian F. Tyson* \\ Department of Chemistry, University of Massachusetts, Amherst, Massachusetts 01003
}

\section{Susan McIntosh}

Perkin-Elmer Corporation, Inorganic Analysis Division, 50 Danbury Road, Wilton, Connecticut 06897

\section{INTRODUCTION}

Flow injection analysis has been used recently for CVAAS determinations. ${ }^{1-5}$ However, only two flow injection systems have been used for the determination of mercury as an organomercury species. ${ }^{1,5}$ One system described ${ }^{1}$ employed a strong oxidizing acid with an oxidizing agent and an external heat source to oxidize the organomercury species prior to reduction. It appears that the rather large internal volume of the system contributed to the poor detection limit of 20 $\mathrm{ng} / \mathrm{mL} \mathrm{Hg}$ (calculated as twice the average baseline signal) and low sample throughput of 20 per hour. More recently, the use of on-line microwave heating was described. ${ }^{5}$ However, as all of the samples were treated off-line with an oxidative procedure, the microwave heating appeared to have had no effect on the organomercury oxidation process.

In this work, we describe a rapid, precise, and accurate flow injection method for the determination of total mercury in a variety of sample types, including waters and urine, at concentrations down to $0.1 \mathrm{ng} / \mathrm{mL}$. The need for an external heat source is eliminated, the sample pretreatment procedure is simplified, and excellent sensitivity is obtained as a result of the improved release of mercury vapor arising from the elevated operating temperature. The possible beneficial effects of an amalgam trapping device were investigated. Method performance was determined by spiking a variety of sample types with known amounts of organomercury compounds and by the analysis of NIST SRM 2670 freeze-dried urine.

\section{EXPERIMENTAL SECTION}

Apparatus. A FIAS 200 flow injection atomic spectrometry system supplied by Perkin-Elmer was used for all experiments. This flow injection system consists of pumps, Tygon pump tubing, 1.0-mm-i.d. Teflon manifold tubing, a gas-liquid separator, and a quartz T-cell with resistive furnace heating. Pump tubing for pumping concentrated sulfuric acid was made of Viton and was obtained through Cole-Parmer. The flow injection manifold constructed for total dissolved mercury determinations is shown in Figure 1. The gas-liquid separator supplied by Perkin-Elmer was a cylindrical chamber partially filled with glass beads with

(1) Birnie, S. E. J. Autom. Chem. 1988, 10, 140-143.

(2) de Andrade, J. C.; Pasquini, C.; Baccan, N.; Van Loon, J. C. Spectrochim. Acta 1983, 38B, 1329-1338.

(3) Fang, Z.; Xu, S.; Wang, X.; Zhang, S. Anal. Chim. Acta 1986, 179, 325-340.

(4) Pasquini, C.; Jardim, W. F.; de Faria, L. C. J. Autom. Chem. 1988, $10,188-191$.

(5) Welz, B.; Tsalev, D.; Sperling, M. Anal. Chim. Acta 1992, 261, 91-103.

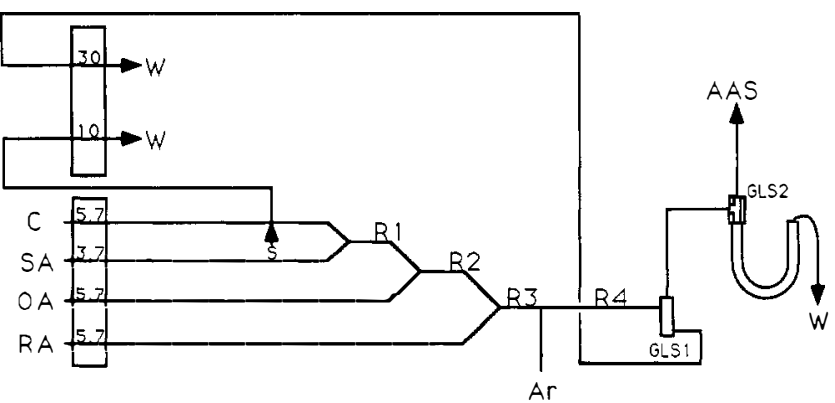

Figure 1. Optimized manifold design for the determination of total dissolved mercury in environmental water samples. $C$ is the aqueous carrier solution, SA is concentrated sulfuric acid, OA is $5 \%(\mathrm{~m} / \mathrm{v})$ potassium persulfate oxidizing agent, and RA is $10 \%(\mathrm{~m} / \mathrm{v})$ tin(II) chloride reducing agent in $10 \%$ (v/v) hydrochloric acld. Flow rates are shown above the individual streams. GLS1 and GLS2 refer to the first and second stage gas-llquld separators used in the system, respectively. $R 1$ is $30 \mathrm{~cm}, R 2$ is $150 \mathrm{~cm}, R 3$ is $30 \mathrm{~cm}$, and the sample volume is $500 \mu L$.

a separate connection for pumping spent liquid to waste. To avoid the possible spraying of hot acid from the connections made to the gas-liquid separator, the silicon rubber connectors supplied were replaced with Tygon tubing fastened with wire ties. The pump tubing leading from the gas-liquid separator to waste was made of Tygon or Viton, with Viton being preferable for reasons of greater safety and resilience. A micro-U-tube (250 $\mu \mathrm{L}$ total volume) was placed in the vapor transfer line to remove condensed water vapor prior to the quartz cell. The entire vapor transfer apparatus is shown in Figure 2. A Perkin-Elmer 3100 atomic absorption spectrometer equipped with a Perkin-Elmer mercury hollow cathode lamp operated at $7 \mathrm{~mA}$ was used for all determinations. A spectral bandpass of $0.7 \mathrm{~nm}$ at the $253.7-\mathrm{nm}$ line was used.

Pump action, injection timing, quartz cell temperature, and all data processing were controlled through Perkin-Elmer FIAS 200 software on a Digital DECStation personal computer.

A Perkin-Elmer amalgam system was used in parts of the study. This system traps the liberated mercury vapor on a gold/platinum gauze prior to thermal desorption and detection.

Reagents. Distilled, deionized water produced by a Barnstead E-Pure system was used in all solutions. ACS reagent-grade concentrated sulfuric acid, nitric acid, and hydrochloric acid (Fisher Scientific) were used throughout the study. Tin(II) chloride reducing agent in $10 \%$ (v/v) hydrochloric acid was prepared fresh daily by dissolving the appropriate mass of tin(II) chloridedihydrate (Fisher Scientific) in $50 \mathrm{~mL}$ of concentrated hydrochloric acid and diluting this to $500 \mathrm{~mL}$ with distilled, deionized water. This was purged with argon for $30 \mathrm{~min}$ prior to use. Potassium persulfate oxidizing agent was prepared fresh daily by dissolving $25 \mathrm{~g}$ of reagent-grade potassium persulfate 


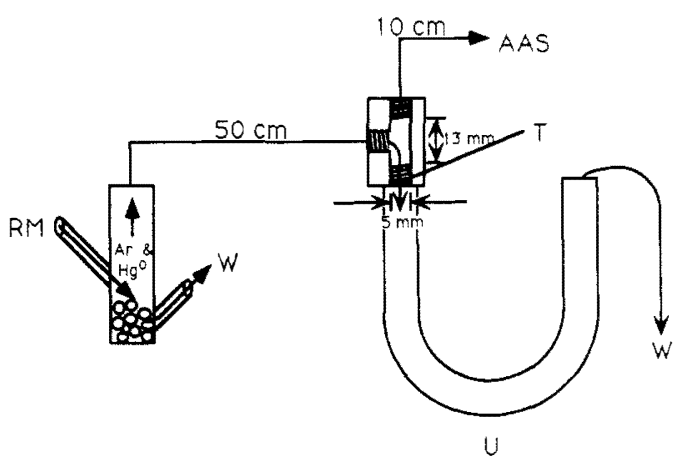

Figure 2. Design of gas-llquld separation scheme. The first-stage gas-liquid separator used was supplied by Perkin-Elmer. A secondstage gas-liquid separator was necessany to remove the condensed water vapor that was generated as a result of the heat of dilution in the manlfold. RM going into GLS1 refers to the reaction mixture leaving the manifold. T (GLS2) refers to a plece of clear Plexlglass drilled by the dimensions shown. U refers to a piece of $1 / 4-$ in.-l.d. Tygon tubing connected in the conflguration shown, keeping the llquid level constant.

(Fisher Scientific) in $500 \mathrm{~mL}$ of distilled, deionized water and heating gently on a hot plate until dissolution was complete.

Inorganic mercury standards were prepared by appropriately diluting a $1000 \mathrm{mg} / \mathrm{L} \mathrm{Hg}$ as mercury nitrate aqueous standard solution (Fisher, $\mathrm{Hg}\left(\mathrm{NO}_{3}\right)_{2}$ ) with $5 \%(\mathrm{v} / \mathrm{v})$ nitric acid. Methylmercury chloride standards were prepared by appropriately diluting a $1000 \mathrm{mg} / \mathrm{L} \mathrm{Hg}$ as methylmercury chloride aqueous standard solution (Johnson-Matthey, $\mathrm{CH}_{3} \mathrm{HgCl}$ ) with $5 \%$ nitric acid. Phenylmercury acetate standards were prepared by dissolving $167.8 \mathrm{mg}$ of the solid (Fluka, $\mathrm{C}_{8} \mathrm{H}_{8} \mathrm{HgO}_{2}, 99 \%$ purity) in $100 \mathrm{~mL}$ of distilled, deionized water and sonicating the mixture for $10 \mathrm{~min}$. This gave a standard solution of $1000 \mathrm{mg} / \mathrm{L} \mathrm{Hg}$ as phenylmercury acetate, which was then diluted appropriately with $5 \%$ nitricacid. Sodium ethylmercurithiosalicylatestandards were prepared by dissolving $201.8 \mathrm{mg}$ of the solid (Sigma, $\mathrm{C}_{9} \mathrm{H}_{9-}$ $\mathrm{HgNaO}_{2} \mathrm{~S}, 98 \%$ purity) in $100 \mathrm{~mL}$ of distilled, deionized water. This gave a standard solution of $1000 \mathrm{mg} / \mathrm{L} \mathrm{Hg}$ as sodium ethylmercurithiosalicylate, which was then diluted appropriately with distilled, deionized water. NOTE: Mercury compounds, especially organomercury compounds, are highly toxic and can have an appreciable degree of volatility. Perform all sample preparations in a well-ventilated fume hood. Consult local authorities as to the proper disposal of mercury compounds.

Hydroxylamine hydrochloride $25 \%(\mathrm{~m} / \mathrm{v})$ was prepared by dissolving $25 \mathrm{~g}$ of solid hydroxylamine hydrochloride (Fisher Scientific) with distilled, deionized water in a $100-\mathrm{mL}$ volumetric flask and diluting to volume. Reagent-grade potassium permanganate solid (Aldrich) was used in the form obtained.

Preparation of Samples. Aqueous samples of drinking water, river water, and pond water were spiked with $20 \mathrm{ng} / \mathrm{mL} \mathrm{Hg}$ as methylmercury chloride and were analyzed directly.

Synthetic waste effluent samples were prepared by dissolving appropriate amounts of solid oxalic acid in distilled, deionized water to give chemical oxygen demand (COD) values of up to $1068 \mathrm{ppm}$. These were then spiked with $20 \mathrm{ng} / \mathrm{mL} \mathrm{Hg}$ as methylmercury chloride and were analyzed directly.

Urine samples were prepared one of two ways: (a) $5 \mathrm{~mL}$ of urine spiked with $100 \mathrm{ng} / \mathrm{mL} \mathrm{Hg}$ as inorganic mercury, methylmercury chloride, or phenylmercury acetate was diluted to 25 $\mathrm{mL}$ (50 mL in the case of SRM 2670 urine) with distilled, deionized water and analyzed directly or (b) $5 \mathrm{~mL}$ of urine spiked with 100 $\mathrm{ng} / \mathrm{mL} \mathrm{Hg}$ as inorganic mercury, methylmercury chloride, or phenylmercury acetate was placed in a $125-\mathrm{mL}$ beaker and 0.75 $\mathrm{g}$ of solid potassium permanganate was added. Concentrated sulfuric acid $(5 \mathrm{~mL})$ was added in $0.5-1.0 \mathrm{~mL}$ aliquots, allowing the vigorous reaction to subside before the next aliquot was added. The digest was then clarified by the dropwise addition of $25 \%$ hydroxylamine hydrochloride solution (approximately $1 \mathrm{~mL}$ ). The resulting solution was then transferred quantitatively to a $25-\mathrm{mL}$ volumetric flask ( $50 \mathrm{~mL}$ in the case of SRM 2670 urine) and diluted to volume with distilled, deionized water and analyzed.

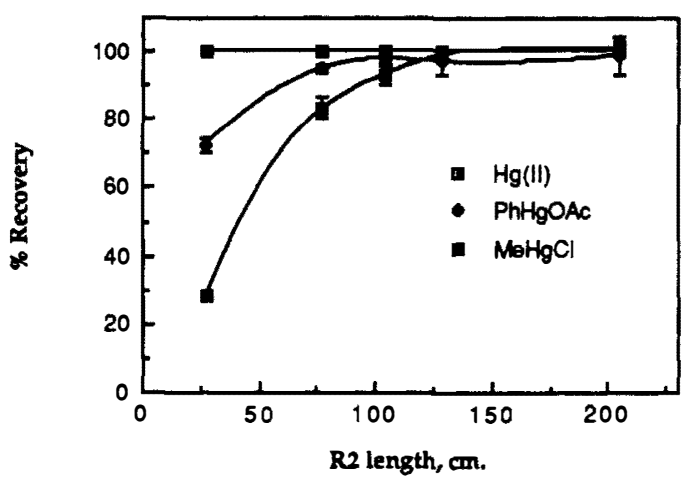

Figure 3. The recovery of various organomercury compounds as affected by changing the length of R2. All recoveries are based on signals relative to a $20 \mathrm{ng} / \mathrm{mL}$ inorganic mercury standard. Flow rates are those shown in Figure 1. Bars in the ydrection are $95 \%$ confidence intervals.

Optimization of Manifold Parameters. The manifold was designed to yield quantitative recoveries for all of the mercury species examined, as well as maximum sensitivity for mercury. To obtain maximum recoveries, the variables of oxidizing agents used and oxidation coil length were examined. To obtain maximum sensitivity, the variables of solution and argon flow rates, sample volume, tin(II) chloride reductant concentration, and reduction coil length were examined.

\section{RESULTS AND DISCUSSION}

Optimization of Organomercury Recoveries. Preliminary studies used concentrated sulfuric acid as the sole oxidizing agent. Consistently higher recoveries were obtained for the phenylmercury acetate species than for the methylmercury chloride species in a distilled, deionized water matrix. It was concluded that the methylmercury chloride species was more difficult to oxidize to the inorganic state and would require more robust oxidizing conditions. The possibility of using solid potassium permanganate as an online oxidizing agent in the manifold was examined but was found to be impractical because of the build-up of solid manganese dioxide on the walls of the tubing. Other investigators ${ }^{1,6}$ have found that treatment with potassium persulfate and concentrated sulfuric acid produced complete oxidation of organomercury species without the formation of solid reaction products. Thus, $5 \%(\mathrm{~m} / \mathrm{v})$ potassium persulfate solution was merged after the addition of the concentrated sulfuric acid to produce complete oxidation of the organomercury species to the inorganic state prior to reduction.

It was found that increasing the length of the reaction coil (R2 in Figure 1) after addition of the potassium persulfate resulted in increased recoveries of the organomercury species. Quantitative recoveries were obtained for both phenylmercury acetate and methylmercury chloride species with a reaction coil of $1.3 \mathrm{~m}$ or longer, as shown in Figure 3. The length of $\mathrm{R} 2$ was set to $1.5 \mathrm{~m}$ since this length was well on the recovery plateau shown in Figure 3, while still contributing to shorter sample through-put times relative to longer lengths. It should be noted that the use of an external heat source was not employed, since the heat of dilution of concentrated sulfuric acid is quite appreciable. A temperature of approximately $85^{\circ} \mathrm{C}$ was produced by a $1: 1$ dilution. This heat is thus exploited in the organomercury oxidation process.

Optimization of Mercury Sensitivity. The argon flow rate was varied between 25 and $150 \mathrm{~mL} / \mathrm{min}$. It was found that a flow of 25-50 $\mathrm{mL} / \mathrm{min}$ produced maximum sensitivity, with a steady decrease in signal for higher argon flow rates. Argon flow rates lower than $25 \mathrm{~mL} / \mathrm{min}$ cannot be measured

(6) El-Awady, A. A.; Miller, R. B.; Carter, M. J. Anal. Chem. 1976, 48, $110-116$. 
reliably with the flow meter used in the system and were thus not examined. The optimum argon flow is considerably less than the recommended value of $100 \mathrm{~mL} / \mathrm{min}$ for a $\operatorname{tin}(\mathrm{II})$ chloride reduction required when a dilute acid carrier stream is used in this system. It is considered that less argon is needed to strip the elemental mercury from solution due to the increased temperature and consequently reduced solubility and increased vapor pressure of the elemental mercury. Furthermore, this decreased argon flow allows for a greater residence time of the mercury vapor in the atom cell.

Total solution flow rate was examined for its effect on the sensitivity of the system. Keeping all of the flow rates proportional (the ratio of the flows of $\mathrm{H}_{2} \mathrm{O}$ carrier:36 $\mathrm{N} \mathrm{H}_{2}$ $\mathrm{SO}_{4}: 5 \% \mathrm{~K}_{2} \mathrm{~S}_{2} \mathrm{O}_{8}: 10 \% \mathrm{SnCl}_{2}$ being 1.54:1.00:1.54:1.54), it was found that a total flow rate of $20.8 \mathrm{~mL} / \mathrm{min}$ resulted in maximum sensitivity and minimum precision. Further increases in flow rate would be beneficial for sample throughput but would result in a decreased residence time leading to lowered recoveries for organomercury species, especially methylmercury. This effect may be seen from Figure 3 in which reaction "tube length" may be considered equivalent to "residence time".

The effect of sample volume was also examined for its effect upon system sensitivity. Increasing the sample volume above the manufacturer's recommended value of $500 \mu \mathrm{L}$ resulted in a proportional increase in peak area. However, the increase in peak height was not proportional-a $6 \%$ increase in peak height for a $36 \%$ increase in sample volume and a $19 \%$ increase in peak height for a $92 \%$ increase in sample volume. It was decided that increasing the sample volume above $500 \mu \mathrm{L}$ did not result in worthwhile gains in peak height sensitivity.

The effect of the concentration of tin(II) chloride in the range $2-10 \%(\mathrm{~m} / \mathrm{v})$ was examined. It was found that there was only a slight increase in sensitivity for tin(II) chloride concentrations over $5 \%$, with the maximum sensitivity being achieved at $10 \%$. It is possible that the relatively high concentration of tin(II) chloride in this system is necessary to reduce the excess oxidizing agent present at the point of reduction.

The length of the reduction coil (R3 in Figure 1) was examined for its effect on sensitivity over the range 10-70 $\mathrm{cm}$. It was found that optimum sensitivity and precision were obtained with a reduction coil length of $30 \mathrm{~cm}$.

Interferences from Other Elements. It has been reported that the use of potassium persulfate and potassium permanganate in the oxidation of organomercury compounds can result in a positive spectral interference if there is an excess of chloride in the sample ${ }^{7}$ due to the formation of chlorine. Concentrations of up to $2.0 \%$ chloride (as sodium chloride) in the sample were shown to have no effect on the signal in this system. While the oxidation of chloride to chlorine gas may be thermodynamically favorable, it would appear that the short residence time of the samples in this FI system produces kinetic masking.

The tolerance for sulfide in the system was examined by spiking $20 \mathrm{ng} / \mathrm{mL} \mathrm{Hg}$ as $\mathrm{Hg}$ (II) into varying concentrations of sulfide as sodium sulfide. Up to $1 \mathrm{mg} / \mathrm{L}$ of sulfide can be present in the sample before there is a decreased signal recovery of $90 \%$.

Interferences from Water Vapor. It was found that the substantial heat evolved by the FI manifold resulted in water vapor entering and condensing in the vapor transfer line. This water would then be swept into the quartz cell and cause fogging of the end windows of the quartz cell. This

(7) Agemian, H.; Chau, A. S. Y. Anal. Chem. 1978, 50, 13-16.

(8) Littlejohn, D.; Fell, G. S.; Ottaway, J. M. Clin. Chem. 1976, 22, $1719-1723$.

(9) Baselt, R. C. Biological Monitoring Methods for Industrial Chemicals, 2nd ed.; PSG Publishing: Littleton, MA, 1988; pp 198-204. fogging was irreversible and required dismantling, cleaning, and drying of the cell. With no water removal stage in the vapor transfer line, this would occur only $10 \mathrm{~min}$ after system start up. This problem has also been found by other workers. ${ }^{5}$

Initially, a PTFE syringe filter of 1.5-cm diameter and 0.5$\mu \mathrm{m}$ pore size was placed in the middle of the vapor transfer line in an attempt to trap the condensed water vapor. This extended the system operation to $30 \mathrm{~min}$ before the fogging of the quartz end windows occurred. While this is a significant time improvement for the system, it was decided that this was not sufficient for proper performance. A laboratorymade micro-U-tube was then placed in the vapor transfer line to act as a more reliable trap for the condensed water vapor, as shown in Figure 2. After $2 \mathrm{~h}$ of operation, there were no visible signs of moisture condensing in the tubing that connected the micro-U-tube and the quartz atom cell.

Calibration and Limit of Detection. Because the manifold employs the generation of heat on-line by the merging of a distilled, deionized water carrier with concentrated sulfuric acid, it is necessary for the system to reach a state of thermal equilibrium before any measurements are made. It was found necessary to pump for at least $25 \mathrm{~min}$ before thermal equilibrium was reached. The heat generated from the dilution of the concentrated sulfuric leads to an increase in separation efficiency, and thus, as the manifold heats up, the signal steadily gets larger. The signal for a 20 $\mathrm{ng} / \mathrm{mL}$ standard rose from absorbance 0.14 to absorbance 0.28 over the warm up period. This increase is identical to that reported by Welz et al. ${ }^{5}$ The beneficial effects of increasing the temperature have been noted by previous workers. ${ }^{10}$

The system was calibrated with a series of $\mathrm{Hg}$ (II) standards up to $20 \mathrm{ng} / \mathrm{mL} \mathrm{Hg}$. A least squares regression analysis of a six-point calibration for peak height produced the equation $H=1.38 \times 10^{-2} \mathrm{C}+3.12 \times 10^{-3}$, where $H$ is peak height absorbance and $C$ is concentration ( $\mathrm{ng} / \mathrm{mL}$ ). The correlation coefficient was 1.000 , and the characteristic concentration was $0.31 \mathrm{ng} / \mathrm{mL}$ with a detection limit based on three standard deviations of the blank of $0.14 \mathrm{ng} / \mathrm{mL}$. For peak area the equation was $A=0.229 C-3.81 \times 10^{-2}$, where $A$ is peak area (absorbance seconds) with a correlation coefficient of 0.999 . The characteristic concentration was $0.019 \mathrm{ng} / \mathrm{mL}$ with a detection limit, based on three standard deviations of the blank, of $0.23 \mathrm{ng} / \mathrm{mL}$. The relative standard of deviation of the signal for a $10 \mathrm{ng} / \mathrm{mL} \mathrm{Hg}$ (II) standard was $1.4 \%$ for both peak height measurements and peak area measurements ( $n$ $=3$ ).

The Perkin-Elmer amalgam system was used in conjunction with the manifold to examine its effect on manifold sensitivity. It was determined that there are no appreciable gains to be made in detection and sensitivity by using this trapping device with this manifold and a $500-\mu \mathrm{L}$ sample volume for either peak height or peak measurements. This was partly due to the rather large blank values obtained and partly due to the kinetics of the gas-liquid separation process. This process appears to be rapid in comparison with the rate of release by thermal desorption from the amalgam, and thus no gains will accrue from the use of the amalgam based on improved release of mercury into the vapor phase. Any increase in sensitivity would require the use of larger sample volumes or multiple injections prior to thermal desorption of the mercury.

Recovery of Organomercury Species. All three of the organomercury species examined in this study-phenylmercury acetate, sodium ethylmercurithiosalicylate, and methylmercury chloride - were all fully recovered in a dis-

(10) Goulden, P. D.; Anthony, D. H. Anal. Chim. Acta 1980, 120, 129- 
Table I. Recoveries of Various Mercurial Species in a Variety of Matricesa

\begin{tabular}{|c|c|c|c|c|c|}
\hline sample type & $\mathrm{Hg}$ found $_{\mathrm{ppb}}$ & $\mathrm{Hg}$ added $_{\mathrm{ppb}}$ & $\mathrm{Hg}$ form added & $\mathrm{Hg}$ recovered $_{\mathrm{ppb}}$ & $\%$ recovered \\
\hline $\mathrm{DD} \mathrm{H}_{2} \mathrm{O}$ & ND & 20 & $\mathrm{MeHgCl}$ & $20.8 \pm 1.0$ & $104 \pm 5(3)$ \\
\hline $\mathrm{DD} \mathrm{H}_{2} \mathrm{O}$ & ND & 20 & PhHgOAc & $20.0 \pm 0.4$ & $100 \pm 2(3)$ \\
\hline $\mathrm{DD} \mathrm{H}_{2} \mathrm{O}$ & ND & 20 & $\mathrm{EtHgSPhCO}{ }_{2}^{-} \mathrm{Na}^{+}$ & $21.2 \pm 1.4$ & $106 \pm 7(3)$ \\
\hline drinking water & ND & 20 & $\mathrm{MeHgCl}$ & $22.4 \pm 0.8$ & $112 \pm 4(3)$ \\
\hline river water* & ND & 20 & $\mathrm{MeHgCl}$ & $18.9 \pm 2.0$ & $94 \pm 10(3)$ \\
\hline pond water* & ND & 20 & $\mathrm{MeHgCl}$ & $19.4 \pm 3.0$ & $97 \pm 15(4)$ \\
\hline synthetic waste effluent & ND & 20 & $\mathrm{MeHgCl}$ & $20.8 \pm 0.2$ & $104 \pm 1(3)$ \\
\hline \multirow[t]{3}{*}{ urine-proc. A } & 3.5 & 100 & $\mathrm{Hg}(\mathrm{II})$ & $100.5 \pm 1.5$ & $97 \pm 2(3)$ \\
\hline & 3.5 & 100 & $\mathrm{PhHgOAc}$ & $45.0 \pm 1.0$ & $45 \pm 1(3)$ \\
\hline & 3.5 & 100 & $\mathrm{MeHgCl}$ & $3.5 \pm 0.5$ & $<1(3)$ \\
\hline \multirow[t]{3}{*}{ urine-proc. B } & 4.5 & 100 & $\mathrm{Hg}(\mathrm{II})$ & $105.0 \pm 1.0$ & $100 \pm 1(4)$ \\
\hline & 4.5 & 100 & PhHgOAc & $112.0 \pm 4.5$ & $107 \pm 5(5)$ \\
\hline & 4.5 & 100 & $\mathrm{MeHgCl}$ & $101.5 \pm 4.0$ & $97 \pm 4(4)$ \\
\hline
\end{tabular}

${ }^{a}$ ND indicates no mercury was measured in the unspiked sample matrix. The asterisk refers to recoveries that were obtained using the amalgam trap prior to detection. All \pm terms refer to $95 \%$ confidence intervals. For sample pretreatment procedures for urine refer to text. The number of replicates $(n)$ for each determination are shown in parentheses next to each \% recovered.

tilled, deionized water matrix relative to an inorganic mercury standard. The results are shown in Table I.

As a means of determining method performance, drinking water, river water, pond water, and a synthetic waste effluent sample were spiked with $20 \mathrm{ng} / \mathrm{mL} \mathrm{Hg}$ as methylmercury chloride. Methylmercury chloride was chosen for the validation studies since it seems to be the organomercury species most difficult to oxidize, as well as being the most prevalent form of organomercury found in natural waters. The results for the analysis of waters are shown in Table I.

For the urine samples the procedure that involves diluting the urine 1:5 and analyzing directly yielded quantitative recoveries of inorganic mercury, while phenylmercury acetate was only partially recovered and methylmercury chloride was not recovered at all. It is considered that this was due to the nature of the urine matrix, which competed with the organomercury species for available oxidizing agent. The rapid potassium permanganate/sulfuric acid digestion procedure resulted in complete recovery of the organomercury species with the same manifold. These results are shown in Table I. The results obtained using both procedures for the analysis of SRM 2670 urine (see Table II) would suggest that the mercury present in the material is in the inorganic state, as both procedures yield quantitative results. The ability to determine only inorganic mercury directly in urine is still a useful procedure, since urine mercury determinations are usually performed to screen an individual's exposure to
Table II. Recoveries of Total Mercury in SRM 2670

Freeze-Dried Urine for Two Different Sample Pretreatment Procedures ${ }^{a}$

\begin{tabular}{lccc}
\hline & \multicolumn{2}{c}{ Hg found $(\mathrm{ng} / \mathrm{mL})$} & \\
\cline { 2 - 3 } & peak height & peak area & Hg certified $(\mathrm{ng} / \mathrm{mL})$ \\
\hline procedure A & $88 \pm 9(4)$ & $94 \pm 10(4)$ & $105 \pm 8$ \\
procedure B & $92 \pm 9(3)$ & $94 \pm 8(3)$ & $105 \pm 8$
\end{tabular}

a The number of replicates $(n)$ for each determination is shown in parentheses next to the amount of $\mathrm{Hg}$ found. All \pm terms refer to $95 \%$ confidence intervals. For the two sample pretreatment procedures, refer to the text.

inorganic or elemental mercury. ${ }^{8,9}$ The results obtained in this study suggest that a simple procedure for the speciation of mercury in urine may be based on (a) a total mercury determination (off-line oxidation) and (b) an inorganic mercury determination (on-line oxidation). These procedures would be considerably simpler than those proposed by Goulden and Anthony. ${ }^{10}$

\section{ACKNOWLEDGMENT}

Financial support and the donation of equipment by the Perkin-Elmer Corp. is gratefully acknowledged.

RECEIVED for review July 13, 1992. Revised manuscript received November 5, 1992. Accepted November 11, 1992. 